\title{
DLE Progressing to Squamous Cell Carcinoma: A Case Report
}

\author{
Karki S', Jha A K ${ }^{2}$
}

${ }^{1}$ HIV AIDS Counsellor, Consultant Dermatologist; DI Skin Hospital Maharajgunj, Kathmandu, Nepal, ${ }^{2}$ Consultant Dermatologist and Founder Chairman, DI Skin Hospital Maharajgunj, Kathmandu, Nepal, Professor and Head of Department Nepal Medical College, Attrarkhel, Jorpati, Kathmandu, Nepal

\begin{abstract}
A 90 years female diagnosed as a case of Discoid lupus erythematosus (DLE) developed Squamous cell carcinoma from the lesions over a period of 5 years due to treatment gap and late follow up. Diagnosis was based on clinical aspects (erythematous, nodular and scanty bleeding), dermoscopic features and histopathological examination,the absence of systemic involvement and routine laboratory parameters, which registered all within normal range.

SCC in a patient with DLE is rare in Nepalese patients. It is every essential to counsel the diagnosed cases of DLE and warn all patients about all the possible outcomes and compliance with medications should be ensured.

Key word: Discoid lupus erythematosus (DLE) , Squamous cell carcinoma (SCC), Dermoscopy
\end{abstract}

\section{Introduction}

$\mathrm{D}$ iscoid lupus erythematosus (DLE) is a benign, autoimmune disorder of the skin, clinically characterized by red scaly patches which heal with atrophy, scarring and pigmentary changes, and histopathologically by stratum corneum hyperkeratosis and follicular plugging, thinning and flattening of stratum malpigii, hydropic degeneration of the basal layer also referred to as liquiefaction degeneration, which is characterised by vacuolar spaces beneath and between basilar keratinocytes which shows individual cell necrosis (apoptosis) and acquire elongated contours like their superficial counterparts rather than their normal columnar appearance (squamatisation). Frequently, the undulating rete ridge pattern is lost and is replaced by a linear array of squamatized keratinocytes.

Thickening and tortuosity of the basement membrane correlate with deposition of immune reactants. The stromal layer shows a predominantly lymphocytic infiltrate arranged along the dermal-epidermal junction, around the hair follicles and other appendages, and in an interstitial pattern; interstitial mucin deposition; edema, vasodilatation, slight extravasation of erythrocytes.

\section{Address for correspondence}

Karki Subekcha M.D.

DI Skin Hospital And Research Center

Maharajgunj, Kathmandu, Nepal

E-mail: doctorakarki@gmail.com
Disease commonly affects the sun-exposed areas of the skin. DLE is subdivided into a localized form in which lesions are confined to the face and neck or a disseminated form in which lesions also occur elsewhere on the body. Malignant transformation is a rare complication of this condition. This is a case of squamous cell carcinoma (SCC) developing over lesions of disseminated DLE. The paucity of reports of this complication in literature search warrants its mention. ${ }^{1}$ Subjects with DLE have high-levels of plasmacytoid dendritic cells -derived interferon-a, which mediates both loss of immune tolerance to self-antigens and exaggerated inflammatory state, and supports proliferation and differentiation of hyperactive B-cells. In a few cases, DLE of the lips, scalp, ears or nose may eventually progress to squamous cell carcinoma (SCC). Photosensitivity and the long-standing immunemediated chronic inflammation and dysregulated healing characterized by atrophy, hypopigmentation or scarring inherent to DLE are risk factors for progression to SCC. ${ }^{2}$

\section{Report}

A 90 years female was diagnosed with localised type DLE $6 y e a r s$ ago. She had lesions only over the face. She was undergoing treatment with oral hydroxychloroquine, topical hydrocortisone and sunscreen. However she was lost to follow up. After a late follow up period of 5years and treatment gap there was complaint of few of the older lesion over the left temporal region becoming more erythematous, nodular [Figure 1] and 
scanty bleeding was noted. The nodules had adherent scaling also. On the left temporal area the nodules were around $2 \times 1,2 \times 3 \mathrm{~cm}$ in size [Figure 1]. There was no lymphadenopathy. Systemic examination was normal. Haematological investigation, chest X-ray, ECG was unremarkable.

Based on clinical examination and dermospcopic features Figure1, 2 the lesions were suspected to have malignant transformation, hence, a skin punch biopsy for histopathological evaluation was advised. The histopatological reading was Squamous cell carcinoma, moderately differentiated. Histopathology showed acanthotic epidermis with papillomatosis and parakeratosis. The epidermis shows loss of polarity involving full thickness. The squamous cells were pleomorphic having hyperchromatic nucleus with nuclear rim irregularity. Mitosis constituted 1-3/HPF. Nests of atypical squamoid cells surrounded by large number of lymphocytes infiltrated the upper dermis was seen Figure.3-6. Hence, excisional biopsy was advised.

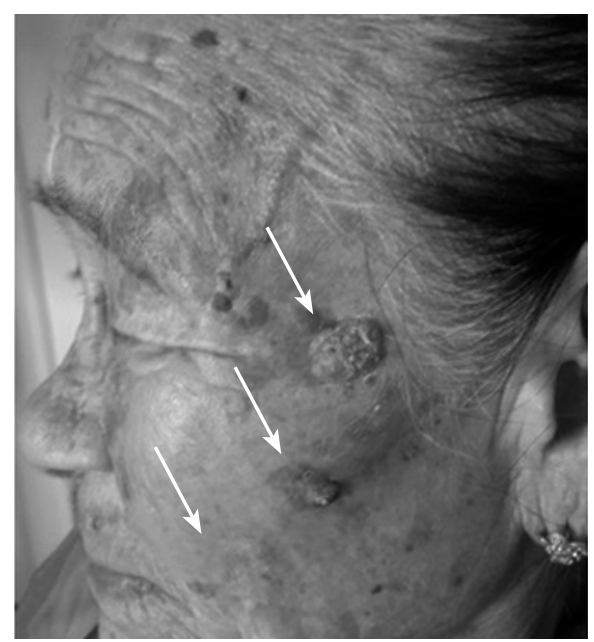

Figure 1: Arrows show previous DLE lesion and the new lesion which developed over the DLE lesion, erythematous, nodules with adherent scaling and scanty bleeding, Biopsy site; $4 \mathrm{~mm}$ Skin Punch Biopsy was done
Patient was advised and underwent a thorough workup to see for metastasis. CBC (complete blood count), LFT (liver function test), RFT (renal function test), TFT (thyroid function test), Thyroid Ultrasound, ECG (electrocardiogram), ANA, Anti-single-stranded DNA done were unremarkable.

She underwent WLE (wide lesional excision) with Rhomboid flap for closure (Figure 7). After excision frozen section were evaluated and the reports was all the margins (anterior, posterior, superior, inferior) free from carcinomatous changes. There was epidermal dysplasia with foci of dermal invasion by atypical squamous cells. Full thickness dysplasia in the epidermis in the form of loss of polarity, moderate to marked atypia, enlarged vesicular nuclei, prominent nucleoli and eosinophilic cytoplasm were seen. Frequent mitosis (2-4/HPF) upto the surface layer was seen. Invasive foci were surrounded by dense desmoplastic reaction. Papillomatosis, parakeratosis, hyperkeratosis, occasional keratin pearl formation and dense lymphocytic infiltrates was noted. Deepest resected base included in the biopsy was free of tumor.

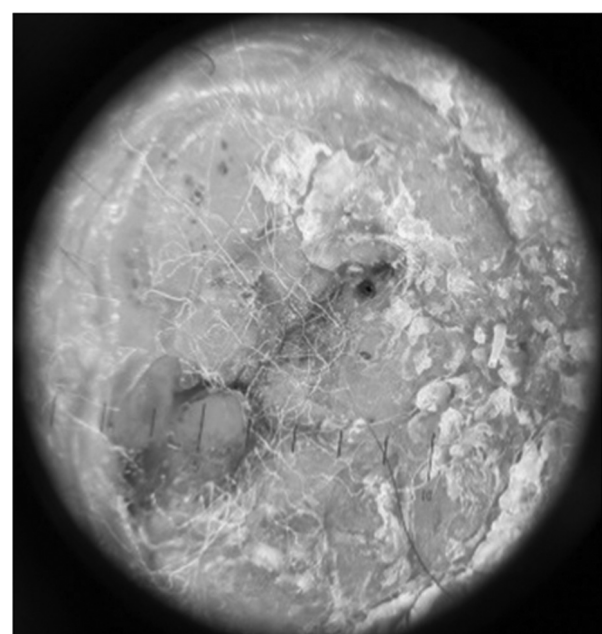

Figure 2: Dermoscopic features showing scale, crusts and bleeding; typical malignant changes were not viewed due to the presence of secondary changes 


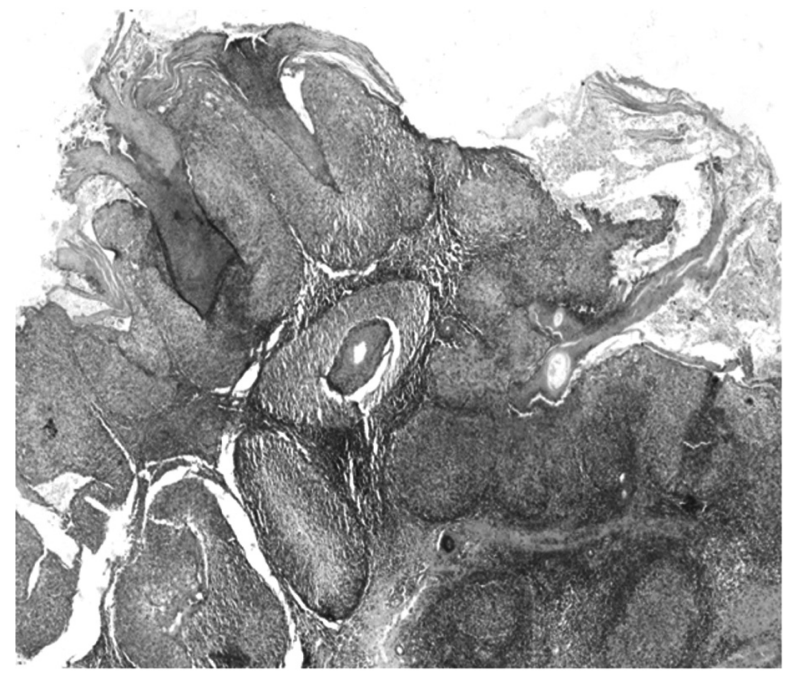

Figure 3: Low power view showing acanthosis papilomatosis and invasion into the dermis

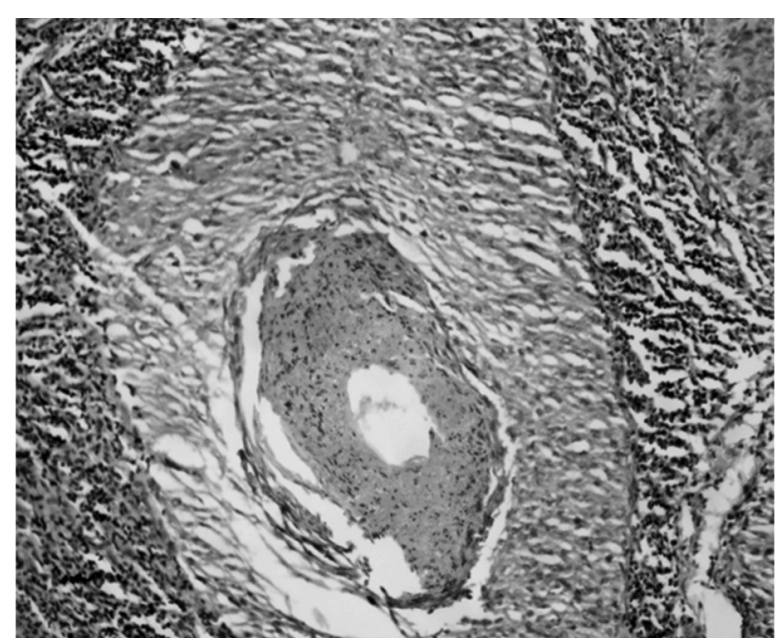

Figure 5: Nests of atypical squamoid cells infiltrating the upper dermis

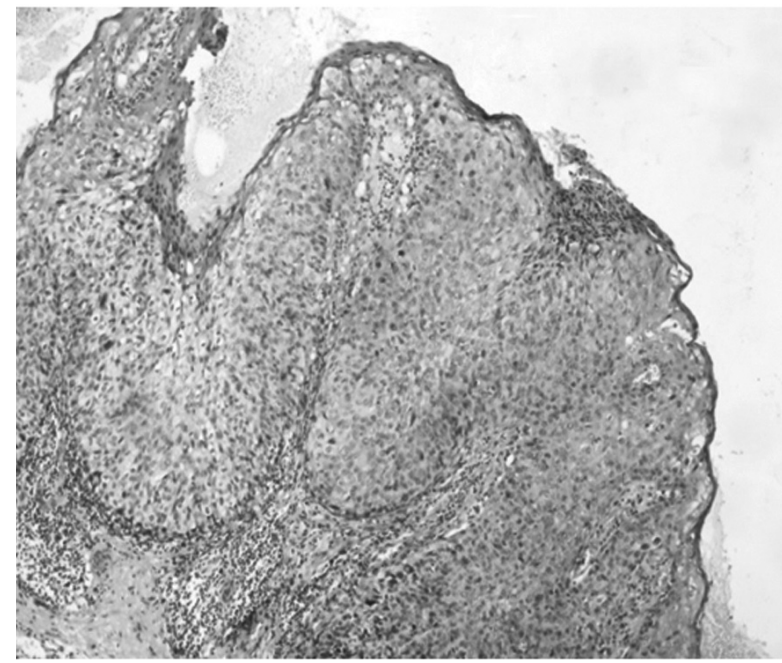

Figure 4: The squamous epithelium showing loss of polarity involving full thickness

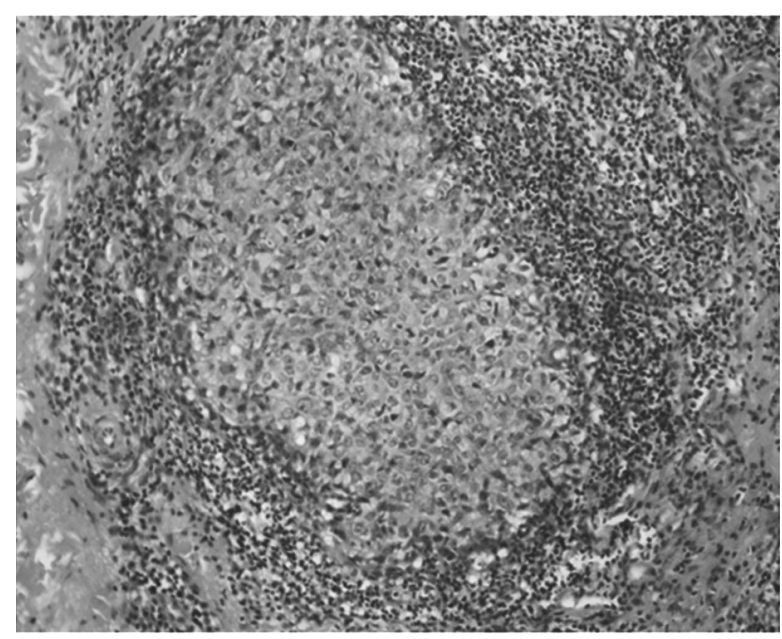

Figure 6: Tumor nests surrounded by large number of lymphocytes.

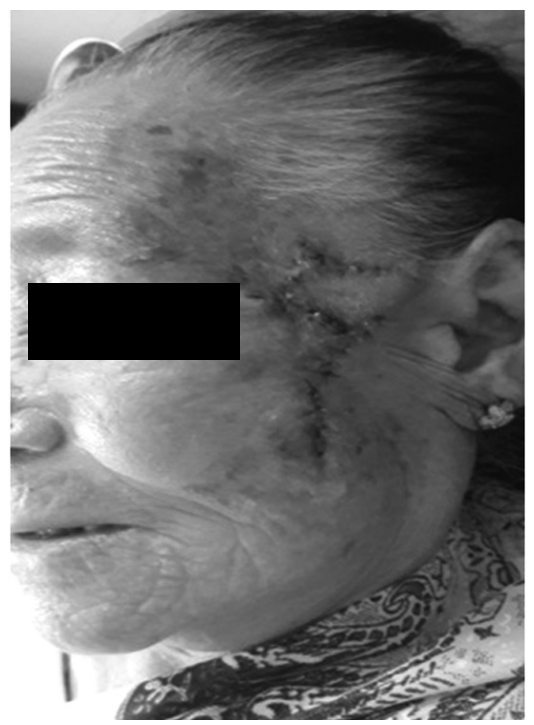

Figure 7: Post-Excisional biopsy, WLE (wide lesional excision) with Rhomboid flap for closure 


\section{Discussion}

SCC and, less commonly, basal cell carcinoma (BCC) are the most feared complications of CCLE. In one study by Millard et al., the incidence was 3.3\% among 120 white patients with CCLE. ${ }^{4}$ The scalp is the most common site involved followed by the lips. Heavy smoking could also be a contributing factor. The scalp is the most common site involved as seen in our patient, followed by the lips. ${ }^{4}$ Squamous cell carcinoma usually arises in skin damaged by actinic rays. Exposure to chemicals such as coal tar, soot, arsenic and a variety of oils and distillation products is also implicated in its pathogenesis. It occasionally occurs in scars following inflammatory or degenerative processes. It is an endstage complication of a wide array of inflammatory skin conditions. ${ }^{5}$ Due to mutation in p53 tumor suppressor gene, there will be defect in apoptosis of keratinocytes that have sustained UV-radiation-induced DNA damage which ultimately lead to SCC. ${ }^{6}$ Usually SCC in DLE develops after about two decades ${ }^{3}$ but earlier onset has also been reported. ${ }^{7,8}$ Cutaneous squamous cell carcinomas that arise secondary to inflammatory and degenerative processes have a much higher rate of metastasis than those developing in sun damaged skin. SCC of lower lip also has a higher incidence of metastasis. $^{9}$

There have been sporadic reports of neoplastic change in DLE which range from SCC and basal cell carcinoma to malignant fibrous histiocytoma and atypical fibroxanthoma. ${ }^{10}$ The interval between development of DLE and SCC has varied from 4 to 20 years. ${ }^{5,7,11}$ Precipitating factors for SCC are age more than 40 years, male sex, sun/ultraviolet ray exposure, skin pigmentation, and chronic inflammatory processes. There is an inverse relation between skin pigmentation and development of SCC because of the protective effect of melanin. ${ }^{6}$

The long-term prognosis of such cases is varied. SCC arising in DLE is regarded as a locally aggressive but lowgrade carcinoma with recurrences. One study reported local recurrences in about $20 \%$ and metastasis in $30 \%$ cases. $^{2} 1$ death has also been reported from multiple metastases. $^{13}$
The risk of a patient with DLE developing systemic lupus erythematosus (SLE) is small. It varies from $1.3 \%$ to about $6.5 \%$. The risk is higher with disseminated DLE (22\%) than in DLE confined to head and neck (1.2\%). ${ }^{3}$ Here, patient did not have any features of SLE, despite having localised DLE for more than 5 years. The presence of laboratory abnormalities in DLE does not itself appear to predispose to the development of SLE. ${ }^{3}$

DLE patients showing signs of nephropathy, presence of arthralgias and elevated ANA titers (> or=1:320) should be carefully monitored, because they may be at risk of developing systemic LE. ${ }^{14}$ Anti-single-stranded DNA antibodies in a patient with DLE may indicate an increased risk of development of SLE. ${ }^{15}$

To conclude SCC in a patient with DLE is rare in Nepalese patients. It is every essential to counsel and warn all patients about all the possible outcomes and compliance with medications should be ensured. Our patient had a successful outcome with local excision of the tumor.

Excisional biopsy microscopic findings: Sections examined show skin tissue comprising of epidermis, dermis and subcutis. The epidermis is dysplastic with foci of dermal invasion by atypical squamous cells. Full thickness dysplasia in the epidermis in the form of loss of polarity, moderate to marked atypia, enlarged vesicular nuclei, prominent nucleoli and eosinophilic cytoplasm are seen. Frequent mitosis (2-4/HPF) upto the surface layer are seen. Invasive foci are surrounded by dense desmoplastic reaction. Papillomatosis, parakeratosis, hyperkeratosis, occasional keratin pearl formation and dense lymphocytic infiltrates are noted. Deepest resected base included in this biopsy is free of tumor. Impression: moderately differentiated squamous cell carcinoma; temporal region.

\section{Acknowledgement}

This case report would not have been possible without the help of Dr.Ram Chandra Adhikari M.D. histopathologists who signed our case as Squamous Cell Carcinoma 


\section{References}

1. Bhat $M R$, Hulmani $M$, Dandakeri $S$, Kambil S M, Gatti R. Disseminated Discoid Lupus Erythematosus Leading To Squamous Cell Carcinoma. Indian J Dermatol 2012; 57(2): 158-161. http://dx.doi.org/10.4103/00195154.94298

2. Molomo E M, Bouckaert M, Khammissa R A G, Motswaledi H M, Lemmer J, Liviu et al. Discoid Lupus Erythematosus-Related Squamous Cell Carcinoma Of The Lip In An HIV-Seropositive Black Male. J Can Ther 2015; 11: 1036. http:// dx.doi.org/10.4103/0973-1482.146107

3. Goodfield MJ, Jones SK, Veale DJ. The Connective Tissue Diseases (Discoid Lupus Erythematosus) In: Burns T, Breathnach S, Cox N, Griffiths C, Editors. Rook's Textbook Of Dermatology. 7th Ed. Oxford: Blackwell Science Ltd; 2004 :5-24.

4. Millard LG, Barker DJ. Development of Squamous Cell Carcinoma In Chronic Discoid Lupus Erythematosus. Clin Exp Dermatol 1978; 3: 161-6. doi: 10.1111/j.1365-2230.1978. tb01480.x

5. Kar BR, Nair V, Ebenezer G, Job CK. Squamous Cell Carcinoma of The Scalp Arising from Chronic Cutaneous Lupus Erythematosus: Report Of Two Indian Patients. Indian J Dermatol Venereol Leprol 2004; 70:236-8. PMID:17642623

6. Grossman D, Leffell DJ. Squamous Cell Carcinoma. In: Wolff K, Goldsmith LA, Gilchrest BA, Paller; Editors. Fitzpatrick's Dermatology In General Medicine. 7th Ed. New York: Mcgrawhill; 2008:1028-36.

7. Nair VL, Chacko M. Disseminated Discoid Lupus Erythematosus with Squamous Cell Carcinoma. Indian J Dermatol Venereol Leprol 1991; 57: 196-7.

8. Dawn G, Kanwar AJ, Dhar S, Nanda R. Squamous Cell Carcinoma Over Disseminated Discoid
Lupus Erythmatosus on Non-Photoexposed Skin. Ind J Dermatol Venereol Leprol 1994; 60:217-8.

9. Kirkham N. Tumors And Cysts Of Epidermis. In: Elder DE, Elenitsas R, Johnson BL, Murphy GF; Editors. Lever's Histopathology Of The Skin. 10th Ed. Philadelphia: Wolters-Lippincott; 2009: 791-849.

10. Matsushita $\mathrm{S}$, Ishihara $\mathrm{T}$, Kageshita $\mathrm{T}$, Egawa K, Miyake T, Ono T. et al, Multiple Squamous Cell Carcinomas Arising In Lesions Of Discoid Lupus Erythematosus. J Dermatol 2004; 31:73-5. http://dx.doi. org/10.1111/j.1346-8138.2004.tb00511.x

11. Pandhi RK, Gupta R, Kumar SA, Bhutani LK. Discoid Lupus Erythematosus In Northern India. Ind J Dermatol Venereol Leprol 1984; 50:97-9.

12. Sulica VI, Kao GF. Squamous-Cell Carcinomaof The Scalp Arising In Lesions Of Discoid Lupus Erythematosus. Am J Dermatopathol 1988; 10:137-41. http://dx.doi. org/10.1097/00000372-198804000-00007

13. MartinS, Rosen T, LockerE. Metastatic Squamous Cell Carcinoma of The Lip.Occurrence In Blacks With Discoid Lupus Erythematosus. Arch Dermatol 1979; 115: 1214. http://dx.doi. org/10.1001/archderm.1979.04010100034014

14. Tebbe B, Mansmann $U$, Wollina $U$, Auer-Grumbach P, Licht-Mbalyohere A, Arensmeier M, Et Al. Markers in Cutaneous Lupus Erythematosus Indicating Systemic Involvement.A Multicenter Study On 296 Patients. Acta Derm Venereol 1997; 77: 305-8. PMid:9228225

15. Costner MI, Sontheimer RD, Provost TT. Lupus Erythematosus. In: Sontheimer RD, Provost TT, Editors. Cutaneous Manifestations of Rheumatic Diseases. 2nd Ed. Philadelphia (PA): Lippincott Williams And Wilkins; 2004: 15-64. 